\title{
Postural corrections after standardised perturbations of single limb stance: effect of training and orthotic devices in patients with ankle instability
}

\author{
A Pintsaar, J Brynhildsen, H Tropp
}

\begin{abstract}
Objective-Soccer players with functional instability of the ankle joint have shown impairment of postural control in single limb stance. The aim of this study was to examine the effect of stance perturbation. Methods-A standardised method for the study of postural corrections after perturbation (Equitest) was used. Female soccer players with and without functional instability were examined.

Results-The subjects showed a relative change from ankle to hip synergy at medially directed translations of the support surface. This impairment was restored after eight weeks of ankle disk training. The effect of a shoe and brace did not exceed the effect of the shoe alone.

Conclusions-Functional instability seems to be related to impaired ability to retain equilibrium in single limb stance by means of ankle corrections. A positive effect of ankle disk training leading to functional restoration was confirmed.
\end{abstract}

(Br F Sports Med 1996;30:151-155)

Key terms: ankle function; perturbation; hip synergy; training

Injuries to the lateral ligaments of the ankle are among the most common injuries occurring in sports and active life. ${ }^{1}$ The most common residual disability after both conservative and surgical treatment is called "instability". Two forms of instability are known. Mechanical instability can be defined as lack of adequate stabilising structures and mobility exceeding the physiological limits; the cause is injury to the capsulo-ligamentous structures. ${ }^{2}$ Functional instability can be defined as recurrent sprains or a feeling of giving way of the ankle, or both; the cause is not clear. Freeman, ${ }^{3}$ who was the first to discuss this disability in functional terms, found functional instability in $40 \%$ of patients who had sustained lateral ligament injury. He suggested that the main cause was proprioceptor damage to the joint, producing proprioceptive deficit and impaired postural control. ${ }^{4}$ Other proposed causes include muscular weakness, ${ }^{5}$ occult instability, and tarsal coalition. ${ }^{6}$

It has been suggested that the regulation of posture and stance is organised in hierarchical and stereotypic patterns. Automatic responses to perturbations, based on two patterns of trunk-leg coordination, have been postulated, ${ }^{7-10}$ including motions of the ankle, knee, and hip joints and associated muscle synergies. The first is the "ankle strategy", when muscle contractions start at the ankle and a torque is generated which rotates the body towards the support surface. The other pattern is "hip strategy", when the hip is flexed or extended in the direction of the sway perturbation. A shear force is then generated against the support surface, which moves the centre of mass back over the centre of support.

However, these data are based on studies of postural control in the sagittal plane in two-leg stance. Few data exist concerning postural control in the frontal plane in single limb stance. While the centre of gravity moves forward in walking and running, the support limb places the support area beneath the centre of gravity, ${ }^{11}$ and anterior-posterior force represents the transfer of body weight along the line of progression. Implicit in the mediolateral force are postural adjustments relative to the narrow support area. We suggest that the medio-lateral component of postural control in single limb stance resembles postural adjustments in the single support phase in walking and running.

Stabilometry, an objective measurement of postural sway by means of the trajectory of the application point for the reaction force, has been used to confirm that ankle joint function correlates well with the ability to maintain equilibrium in single limb stance. ${ }^{12}$ When the ankle is functionally normal, it can govern corrections of posture. If this motion pattern of postural control is insufficient, equilibrium has to be maintained by movement of upper segments of the body. Impaired postural control indicates that the risk of ankle joint injury is increased even in previously uninjured soccer players. ${ }^{13}$ In transverse direction, the body initially aims at keeping movements controlled by supporting the subtalar and ankle joint movements. ${ }^{14}$ If the muscular torque fails and the end of the physiological range of motion is reached, the capsuloligamentous structures are loaded. If they fail, a sprain will occur. ${ }^{1}$ The two malleoli hold the talus on each side, provided that the distance between the talar and medial malleoli is unchanged. This condition is fulfilled only when the malleoli and the ligaments of the inferior tibiofibular joint are intact. ${ }^{15}$ Soccer players with previous ankle problems seem to be injury-prone. ${ }^{13}$ Players 
with functional instability had pathological stabilometry values, ${ }^{12}$ but the degree of mechanical instability was not reflected in the figures. This means that the ankle injury is related to defective postural control and functional instability with a risk for renewed injury.

Two non-operative methods of treatment have been suggested: braces, such as the Air Stirrup, ${ }^{16}$ and ankle disk training. ${ }^{17}$ The latter improves postural control and reduces the risk for injury.

The aim of the present study was to use an available standardised method for the study of postural control and examine the relations between ankle and hip synergies. We also studied the latency of the postural responses after perturbation in order to investigate ankle joint function in single limb stance after perturbation of the support surface.

\section{Methods}

The method used in this study was developed by Lew Nashner (Equitest, Neurocom International Inc, Clackamas, Oregon, USA). ${ }^{101819}$ It has been used for different purposes in the study of postural control..$^{20}$ An objective measurement of stance has been available by means of static posturography such as stabilometry, ${ }^{12}$ which is the quantification of postural sway on a stable platform. However, a dynamic test stresses the postural capacity. This test is performed while the subject stands on a dual force plate enclosed by a visual surround. The platform can be made to move in the anteriorposterior direction by means of a hydraulic servomotor. Embedded within the load cells of the force platform are strain gauges which measure vertical and horizontal (shear) reactive forces exerted against the support surface.

A standard method has been developed for the two-legged stance in the sagittal plane. The force plate system is divided into two semiindependent plates, originally meant for each foot but in this study placed at right angles to the supportive foot so that the anterior part of the foot is on one plate and the posterior on the other. The two force plates were moving together.

Recordings were done with the subject looking straight ahead at a fixed point. The subject stands on one foot on the forceplate, and the other leg is raised and flexed at the knee. The arms are crossed over the chest (figure).

The computerised Equitest records the resultant vertical force in anteroposterior and mediolateral positions. A simple external biomechanical model is used, which is based on the hypothesis that ankle rotation is performed in the plane of the force plate. The sway and the alignment of the centre of mass is calculated. At "ankle strategy" the postural sway of the body is caused by the body rotating as a rigid mass about the ankle joints. In that case there are no horizontal components of force exerted against the support surface. The alternative "hip strategy" means that hip joint activity generates horizontal forces against the support surface that are proportional to the second derivative (acceleration) of the hip joint

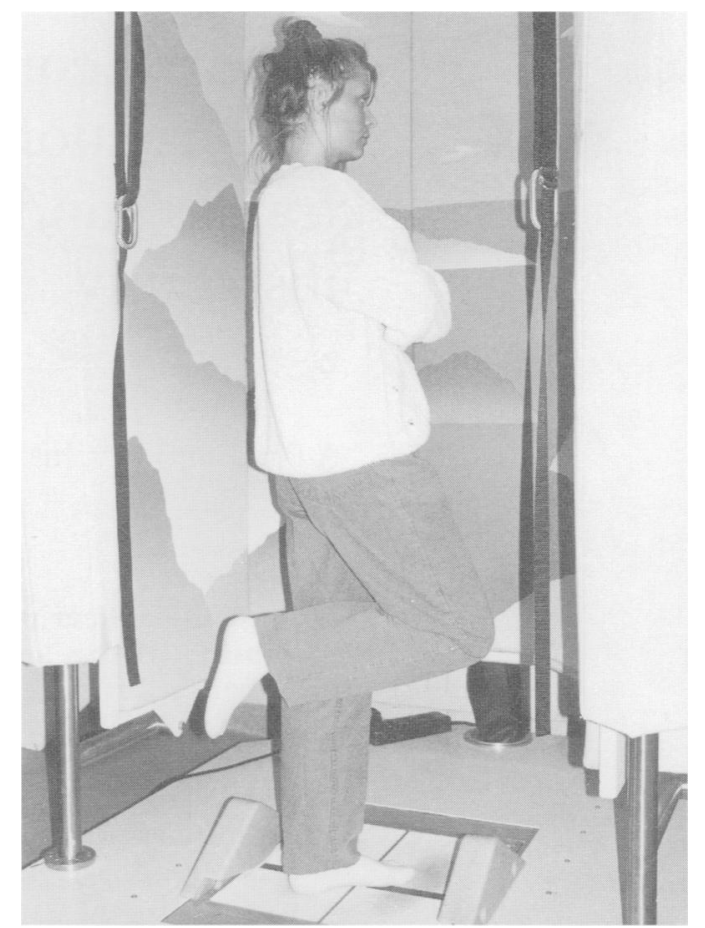

The subject was standing so that the motion axis of the force plate was aligned to the subtalar joint axis. The arms were crossed over the chest and the other limb raised and flexed at the knee.

angle. Conversely, changes in vertical force position during hip sway only occur when the hip sway also causes changes in the centre of mass sway angle.

Constant velocity translations of both plates in forward or backward directions produced mediolateral sway in a direction $90^{\circ}$ to the subtalar axis.

The translations were of different sizes and the amplitudes have been adjusted to compensate for differences in subject height. The duration of each translation is the same regardless of patient height (table 1 ).

For translation trials, delay times between trials were random, between 1.5 and $2.5 \mathrm{~s}$. The mean for three successful recordings is used for the evaluation.

Small and medium translations were used (table 1). Latency is defined as the amount of time it takes after a perturbation starts for the patient to begin actively resisting the perturbation. Measurements start at $100 \mathrm{~ms}$, which is just below the fastest possible human response to force plate perturbations. Active force response latencies are determined separately for the force plates, and consequently for the anterior and posterior parts of the foot. We

Table 1 The following formulas show how the translation sizes are adjusted to patient height $\left(H, 10^{-2} \mathrm{~m}\right)$

\begin{tabular}{lll}
\hline Translation size & Linear amplitude & Equivalent sway \\
\hline $\begin{array}{l}\text { Small translations } \\
\text { Amplitude }\left(10^{-2} \mathrm{~m}\right)=\end{array}$ & $\frac{1 \cdot 27^{\star} \mathrm{H}}{182}$ & $0 \cdot 7$ degrees \\
$\begin{array}{l}\text { Duration }(\mathrm{ms})=250 \\
\text { Medium translations } \\
\text { Amplitude }\left(10^{-2} \mathrm{~m}\right)=\end{array}$ & $\frac{3 \cdot 18^{\star} \mathrm{H}}{182}$ & $1 \cdot 8$ degrees \\
$\begin{array}{l}\text { Duration }(\mathrm{ms})=300 \\
\text { Large translations } \\
\text { Amplitude }\left(10^{-2} \mathrm{~m}\right)= \\
\text { Duration }(\mathrm{ms})=400\end{array}$ & $\frac{5 \cdot 71^{\star} \mathrm{H}}{182}$ & $3 \cdot 2$ degrees \\
\hline
\end{tabular}


used the fastest of the two response latencies for evaluation. The Equitest determines the variations in the mediolateral positions of the centre of vertical force on the plates (perpendicular to the subtalar joint axis of the actual ankle).

Strategy scores show the amount of ankle and hip joint motion used by the patient to correct for the small and medium force plate displacements in medial and lateral directions. Because hip sway and horizontal forces are related by a second order differential equation, it is difficult to calculate actual hip angles from the force plate inputs. The Equitest system estimates the extent of hip swaying by comparing the amplitudes of actual horizontal shear forces to theoretical maximum shear force using the following formula:

Movement strategy $=\frac{25-\left(\mathrm{SH}_{\max }-\mathrm{SH}_{\min }\right.}{25} \star 100$

This calculation assumes that the theoretical difference between the highest positive and lowest negative shear force is $25 \mathrm{lbf}$ (SI units not used by the manufacturer). This theoretical value has been determined by measuring the peak shear forces generated by normal subects who used hip sway to balance on a narrow beam (Nashner $L$, information from the manufacturer). The actual shear force generated during the trial is determined by calculating the difference between the highest shear force $\left(\mathrm{SH}_{\max }\right)$ and the lowest negative shear force $\left(\mathrm{SH}_{\min }\right)$. Movement strategy values near 100 occur with little or no hip sway, while values approach zero when the subject makes maximum use of the hips.

The subjects were randomly selected from a group of 150 female soccer players who were followed prospectively. An evaluation of preventive methods was done throughout the season and in the preseason all players were examined for functional or mechanical ankle instabilities. Mechanical instability was demonstrated by physical examination by a positive anterior drawer sign or a positive talar tilt. All players with functional instability - and thus a

Table 2 The results from small and medium translations performed in medial and lateral directions. The latency time to and the degree of ankle strategy for the adjustments are presented.

\begin{tabular}{|c|c|c|c|c|c|c|c|c|}
\hline & \multicolumn{4}{|c|}{ Latency (ms) } & \multicolumn{4}{|c|}{ Ankle strategy } \\
\hline & \multicolumn{2}{|l|}{ Medial } & \multicolumn{2}{|c|}{ Laternal } & \multicolumn{2}{|c|}{ Medial } & \multicolumn{2}{|c|}{ Laternal } \\
\hline & Small & Medium & Small & Medium & Small & Medium & Small & Medium \\
\hline $\begin{array}{l}\text { Group A } \\
\text { Reference } \\
\text { SD }\end{array}$ & $\begin{array}{r}192 \\
23\end{array}$ & $\begin{array}{r}151 \\
16\end{array}$ & $\begin{array}{r}200 \\
26\end{array}$ & $\begin{array}{r}165 \\
13\end{array}$ & $\begin{array}{l}82 \\
10 \\
\star\end{array}$ & $\begin{array}{r}62 \\
\star 8\end{array}$ & $\begin{array}{r}89 \\
6\end{array}$ & $\begin{array}{l}81 \\
10\end{array}$ \\
\hline $\begin{array}{l}\text { Group B } \\
\text { Before training } \\
\text { SD }\end{array}$ & $\begin{array}{r}205 \\
18\end{array}$ & $\begin{array}{r}161 \\
19\end{array}$ & $\begin{array}{r}192 \\
28\end{array}$ & $\begin{array}{r}166 \\
22\end{array}$ & $\begin{array}{l}73 \\
14\end{array}$ & $\begin{array}{l}54 \\
14 \\
\star\end{array}$ & $\begin{array}{r}86 \\
7\end{array}$ & $\begin{array}{l}71 \\
19\end{array}$ \\
\hline $\begin{array}{l}\text { After training } \\
\text { SD }\end{array}$ & $\begin{array}{r}205 \\
21\end{array}$ & $\begin{array}{r}156 \\
16\end{array}$ & $\begin{array}{r}191 \\
18\end{array}$ & $\begin{array}{r}169 \\
15\end{array}$ & $\begin{array}{r}82 \\
6\end{array}$ & $\begin{array}{l}64 \\
17\end{array}$ & $\begin{array}{r}86 \\
8\end{array}$ & $\begin{array}{l}73 \\
13\end{array}$ \\
\hline $\begin{array}{l}\text { Group C } \\
\text { Without shoe } \\
\text { SD }\end{array}$ & - & - & - & - & $\begin{array}{l}78 \\
{ }_{\star}\end{array}$ & $\begin{array}{l}58 \\
25\end{array}$ & $\begin{array}{r}87 \\
8\end{array}$ & $\begin{array}{r}81 \\
4\end{array}$ \\
\hline $\begin{array}{l}\text { Shoe } \\
\text { SD } \\
\text { Shoe + brace } \\
\text { SD }\end{array}$ & $\begin{array}{r}172 \\
60 \\
191 \\
27\end{array}$ & $\begin{array}{r}152 \\
10 \\
152 \\
13\end{array}$ & $\begin{array}{r}207 \\
26 \\
206 \\
21\end{array}$ & $\begin{array}{r}166 \\
17 \\
168 \\
14\end{array}$ & $\begin{array}{r}89 \\
4 \\
86 \\
7\end{array}$ & $\begin{array}{l}67 \\
23 \\
64 \\
19\end{array}$ & $\begin{array}{r}91 \\
5 \\
91 \\
5\end{array}$ & $\begin{array}{r}80 \\
8 \\
80 \\
8\end{array}$ \\
\hline
\end{tabular}

history of recurrent ankle injuries together with a subjective feeling of the ankle "giving way" - were selected and randomised individually into different treatment groups: control group, training group, braces, etc. Our subjects were randomly selected from among these treatment groups and grouped as follows.

Group $A$ - Twelve players without previous ankle problems. All were tested standing on one limb without shoes.

Group $B$ - Fifteen players with functional instability who underwent an eight week training programme, three to five sessions per week with coordination training on an ankle disk (Codoc, Stockholm, Sweden). Thirteen subjects completed the programme and were examined before and after the training period. They were tested while standing without the shoe.

Group $C$ - Eleven players with mechanical instability without any functional instability. All subjects were found to have a positive anterior drawer sign. No stress $x$ ray was taken. These subjects were supported with an ankle brace (Stabilo, LIC, Stockhom, Sweden). After six weeks of use the women were examined standing without a shoe, with a shoe, as well as with a shoe and brace.

Common statistical methods and principles were used: analysis of variance (ANOVA, paired and two sample $t$ tests, rank sum test, and sign test.

\section{Results}

Large translations, with an amplitude of around $5 \mathrm{~cm}$ were, not evaluated since patients sometimes lost their balance and fell off. Results from small and medium translations were analysed and are presented in table 2 .

We found no differences concerning latencies among the three groups of subjects. However, latency was shorter for the medium than for the small translations.

There were lesser degrees of ankle synergy at medial translation perturbations for the group with functional instability than for those without functional instability. The values were normal after ankle disk training.

The players with ankle problems selected for ankle brace treatment also showed initially impaired ankle synergy patterns. The degree of ankle synergy increased when standing with a shoe on. The brace did not further change the amount of ankle synergy.

\section{Discussion}

The variables found in the Equitest evaluation of postural control are in line with our own studies of postural control in single limb stance. ${ }^{12} 132122$ When the support surface is translated medially the subtalar joint is passively inverted but actively everted, ${ }^{10}$ which is aimed at adjusting the application point of vertical force medially so that the line of gravitation falls lateral to the contact point. However, if the initial passive torque transmitted through from the plate exceeds the inverting muscle force, or if the ankle is inverted so much that the line of gravity acts medial to the subtalar axis, the ankle might be 
injured due to the inverting external torque. This situation can be defined as an unstable position and may be the pathomechanism for "functional instability". ${ }^{6}$

The applied point of application of the reaction force represents the point around which the body is rotating, affected by the torque produced by the gravity force lever arm (the distance between the point of application of the reaction force and the line of action for gravity force).

It is postulated that no shear forces are produced if isolated ankle synergy is used. This is not possible unless the subject is in a complete static position without restitution of the centre of gravity position. If the centre of gravity is accelerated, a shear force is produced according to $F=m a$. The force $F$ is generated either by the above described misalignment of the centre of gravity over the centre of force (ankle synergy) or by hip motion (hip synergy). ${ }^{10}$ We have shown that the size of the shear forces increases with hip synergy compared to ankle synergy, and the actual calculation therefore seems relevant, as it gives a relative measure. However, it cannot be used as an absolute measurement. Hip synergy must be taken into account if the centre of gravity is displaced near or even next to the border of the area of support, or if a large disturbance torque is exerted which cannot be counteracted by the ankle alone. The hip is actively moved and the centre of gravity trajects back over the area of support. Large shear forces are produced due to acceleration forces counteracted by friction from the ground. This is the mechanism of hip synergy, which provides the opportunity to use larger muscle groups acting directly on the upper segments.

At translation the area of support is moved away from the line of gravity. The horizontal shear forces between foot and plate are initially created by the body's inertia. Measurements start after $100 \mathrm{~ms}$, when the correctional movements produce their effects. The subject's aim is to move the body back over the area of support. Medium translation moves the subject a longer distance within the same period of time. It is therefore natural that hip synergies are used to a larger extent at medium than at small translations. Ankle synergy is sufficient only in the theoretical situation when ankle motion can displace the centre of pressure lateral to the line of gravity. If the perturbation appears when the line of gravity is in the periphery of the narrow support area and the ankle is already in a corrective position, there will be greater postural problems and hip synergies have to be taken into account.

The impaired strategy after perturbation among subjects with functional instability is in line with our previous results. ${ }^{22}$ The main finding is that ankle function is related to coordination. Impaired function is related to a change from ankle synergy towards hip synergy for postural adjustments. A restitution has also been shown previously. ${ }^{21}{ }^{23}$ However, this study shows the value of including the type of synergy as a qualitative variable in the pattern of motion. The sensory proprioceptive func- tion at the ankle was not directly evaluated, but if there had been any deficit, latency would probably have been affected. This was not seen.

It has been suggested that bracing improves proprioception and restores impaired postural control. ${ }^{16}$ However, the findings of these investigations involved subjects without shoes. Our results show that the amount of improvement in ankle synergy shown could probably have been provided by wearing shoes. Even if a brace were to improve postural patterns without shoes, the effect would not be clinically significant.

The variables that were impaired among subjects with functional instability were small and medium translations in the medial direction. Although the following correctional motion is eversion, we know from a previous study $^{22}$ that this provocation gives an initial short period (20-30 ms) of inversion.

Different results have been presented aimed at showing the level at which correctional movements are generated. Although central programming of postural response patterns has been suggested, ${ }^{8}$ peripheral sensory information might modify the patterns. Diener et al ${ }^{18}$ have shown 70-100 ms latency responses in the ankle muscles after surface perturbations. The "long loop" responses are not simple unmodified reflexes. We can see that no change in latency was produced by training. Instead, a change in the relation between ankle/hip synergies was seen, suggesting that the postural correction patterns were altered by training. The Equitest system is standardised, simple to use, and provides the possibility of evaluating patients with functional instability of the ankle joint.

In conclusion, we found that female soccer players with functional instability of the ankle joint had less ankle synergy on postural perturbation. Recordings at dynamic equilibrium and dysequilibrium after perturbation showed that regulation of posture is primarily based on corrections at the ankle joint. Ankle disk training caused a restitution of the postural patterns. An ankle brace did not alter the postural patterns, but an improvement was seen when a shoe was worn.

The Equitest recordings were performed by the Odkvist Management Group. The study was supported by grants from the Swedish Sports Research Council and the County of the Swedish
Östergötland.

1 Garrick JG. The frequency of injury, mechanism of injury, and epidemiology of ankle sprains. Am $\mathcal{F}$ Sports Med 1977;5:241-2.

2 Rasmussen O. Stability of the ankle joint. Acta Orthop Scand $1985 ; 56$ (suppl):211.

3 Freeman MAR. Instability of the foot after injuries to the lateral ligament of the ankle. F Bone foint Surg $[\mathrm{Br}]$ 1965;47B:669-77.

4 Freeman MAR, Dean MRE, Hanham IMF. The etiology and prevention of functional instability of the foot. $\mathcal{F}$ Bone foint Surg [Br] 1965;47B:678-85.

5 Staples OS. Result study of injuries to lateral ligaments of the ankle. Clin Orthop 1972;85:50-8.

6 Bosien WR Staples OS, Russel SW. Residual disability following acute ankle sprains. $\mathcal{f}$ Bone foint Surg $[\mathrm{Am}]$ 1955;37A: 1237-43.

7 Forssberg H. Anticipatory postural adjustments during human locomotion. EEG Suppl 1987;39:72-6.

8 Forssberg $\mathrm{H}$, Hirschfeld $\mathrm{H}$. Phasic modulation of postural orssberg H, Hirschfeld H. Phasic modulation of postural activation patterns during human locomotion. In: 76:221-7.

9 Horak FB. Clinical measurement of postural control in adults. Phys Ther 1987;67:1881-5. 
10 Horak FB, Nashner LM. Central programming of postural movements. Adaptation to altered support-surface movements. Adaptation to altered support-

11 Aston JW. Normal patterns of walking and running. In Subotnick SI, ed. Sports medicine of the lower extremity. New York: Churchill Livingstone, 1989.

12 Tropp H, Odenrick P, Gillquist J. Stabilometry in functional and mechanical instability of the ankle joint. Int $\mathcal{F}$ Sports Med 1985;6:180-2.

13 Tropp H, Ekstrand J, Gillquist J. Stabilometry in functiona instability of the ankle and its value in predicting injury. Med Sci Sports Exerc 1984;16:64-6.

14 Inman VT. The joints of the ankle. Baltimore: Williams \& Wilkins, 1976

15 Kapandji IA. The physiology of the joints, vol 2. New York: Churchill Livingstone, 1970:14.

16 Stover CN. Air stirrup management of ankle injuries in the athlete. Am $\mathcal{F}$ Sports Med 1980;8:360-5.

17 Tropp $\mathrm{H}$, Askling C, Gillquist J. Prevention of ankle sprains. Am $\mathcal{F}$ Sports Med 1985;13:259-62.
18 Diener HC, Horak FB, Nashner LM. Influence of stimulus parameters on human postural responses. f Neurophysiol (1)

19 Woolalatt MH, Shumway-Cook A, Nashner LM. Aging and posture control. Changes in sensory organization and and posture control. Changes in sensory organization and muscular

20 Ledin T. Dynamic posturography in evaluating human equilibrium. Linköping: Linköping University, 1990 [medical dissertation No 329]:18-58.

21 Gauffin H, Odenrick P, Tropp H. Effect of ankle disk training on postural control in single limb stance in patients with functional instability of the ankle joint. In f Sports Med 1988;9:141-4.

22 Tropp H, Odenrick P. Postural control in single limb stance. Orthop Res 1988;6:833-9.

23 Fridén $T$, Zätterström R, Lindstrand A, Moritz U. A stabilometric technique for evaluation of lower limb instabilities. Am $\mathcal{F}$ Sports Med 1989;17:118-22. 